DOI 10.7251/SCMED1802080I

UDC 001.891-053.6:378.046.4 COBISS.RS-ID 7836184

\section{An Advice for Young Researchers}

For a young researcher, the best way to improve his skills and develop his research capabilities is to work in established research laboratories where he is enabled to learn modern techniques and how to attack the scientific problems. Today, we have easy communications, including computers and the internet, but direct interactions with the most experienced scientists are the best way for young scientist to advance his research capabilities. Ulf Svante von Euler, Swedish pharmacologist and physiologist presents the best example that illustrates how interaction of a young researcher with established scientists develop his research capabilities and become a well-known scientist ${ }^{1}$.

When Ulf was seventeen (1922), he came in Stockholm to study medicine. As a student, he became interested in research, and in 1926 he attended the Twelfth International Congress of Physiologists in Stockholm where he heard lectures by I. P. Pavlov, E. H. Starling and other great scientists of the time. He also observed a historic demonstration by Otto Loewi on the existence of Vagusstoff in the frog's heart, which would stimulate his own interest and research on mediators of nerve transmission. Prior to this demonstration, Loewi had published several papers on the nature of this chemical substance that slowed the heart, but not all of his research contemporaries were convinced. However, a successful demonstration at the Congress (repeated eighteen times) convinced all critics. Von Euler recalled that these experiments inspired his enduring interest in neurohumoral transmission.

Initially, von Euler was influenced by several well-known Swedish scientists: G. Liljestrand (pharmacologist/physiologist), R. Fåraeus (a hematologist) and $\mathrm{H}$. Theorell (a biochemist, who received the Nobel Prize for Medicine and Physiology in 1955). Ulf defended his doctoral dissertation in 1930 and became a professor of pharmacology. Then, he received a two-year scholarship for postdoctoral studies abroad that enabled him to improve his skills by working with several famous foreign researchers.

The young Ulf von Euler made the most of this opportunity. He spent six months in Hampstead at Sir Henry Dale's laboratory, two months in Birmingham with I. de Burgh Daly, eight months in Ghent with C. Heymans, and three months in Frankfurt with G. Embden. Later, in 1934, he returned to London for six months to work with A. Hill, primarily because Liljestrand advised him instead of pharmacology, rather to devote to physiology because at that time in Sweden this scientific discipline was more appreciated. Towards the end of 1937, he went back to Hampstead for five months to work again with Sir Henry Dale.

Key words: history of medicine, pharmacology, psysiology, neurohumoral transmission, substance b.

(Scr Med 2018:49:80-82)

\section{Rajko Igić}

${ }^{1}$ Faculty of Medicine, University of Banja Luka, Banja Luka, Republic of Srpska, Bosnia and Herzegovina
Manuscript received: September $17^{\text {th }}, 2018$ Manuscript accepted: October $23^{\text {rd }}, 2018$ 


\section{Pharmacologists vs Neurophysiologists}

At the time, two separate camps of researchers held differing views on how nerve impulses were transmitted to effectors sites including nerves, glands and muscles. The battle between these two groups of scientiststhe neurophysiologists and the physiologists-lasted for more than a quarter of a century. The prominent pharmacologist/physiologist, Henry H. Dale (18751968), provided early evidence for neurohumoral transmission. From the 1930s, the neurophysiologists led by John Eccles, studied electrical phenomena in nerves with an oscilloscope. They thought that chemical neurotransmission was too slow to cause the rapid response of skeletal muscles after nerve stimulation. But evidence for chemical neurotransmission continued to accumulate. The pharmacologists of which von Euler was a member declared victory when Paul Greengard described the molecular mechanisms involved in chemical transmission of the nerve impulse. He established two types, fast and slow; the rapid chemical mechanism occurs in less than a millisecond, and transmission of the slow type lasts for a few milliseconds. However, studies in the central nervous system provided a support for neurophysiologists view. The rise of electron microscopy revealed "tight junctions" in some brain areas, which reinforced the idea of electrical transmission across nearly non-existent spaces.

\section{Most important discoveries done by von Euler}

In Henry Dale's laboratory, von Euler worked with John H, Gaddum. They discovered substance P. Nearly forty years later this polypeptide composed of eleven amino acids was isolated, sequenced and synthesized. When discoverers isolated this active substance, they labeled "P" for the preparation. After von Euler returned to Stockholm in 1939, he discovered in sheep prostate glands new substance prostaglandin. As a postdoctoral fellow in Sir Henry Dale's laboratory, he used bioassays of adrenaline and other active substances to study sympathetic neurons. He then isolated noradrenalincontaining vesicles from sympathetic neurons by centrifugal separation and published several important papers on neurohumoral transmission in sympathetic nerves. Initially, not everyone accepted his findings, but many prominent researchers subsequently confirmed his results. He established that noradrenalin was a sympathetic neurotransmitter, and in 1970 he shared Nobel Prize in Physiology and Medicine with Julius Axelrod and Bernard Katz.

\section{Von Euler shared his experiences with other scientists}

Professor von Euler generously shared his experiences with many other scientists, including those in United Kingdom, Germany, Argentina, Yugoslavia, Canada, and USA. He visited Yugoslavia three times. In 1961, Professor Pavao Stern organized a symposium on substance P in Sarajevo, where he brought together a number of leading researchers in the field, including von Euler (Fig.1) and Gaddum, who discovered this biologically active neuropeptide. There were 25 participants at the Sarajevo symposium but von Euler's and Gaddum's mentor, Henry Dale, who was 86 at the time, was unable to make the trip to Sarajevo. Professor Pavao Stern's symposium (Fig.2) not only facilitated the sharing of information between foreign and domestic scientists but also stimulated further research on the effects of Substance P in the central nervous system. Von Euler came to Belgrade in 1968 to attend an international symposium on occasion of the $50^{\text {th }}$ anniversary of the Belgrade Medical School. I meet him there and talked to him. He asked many detailed questions about my own research on acetylcholine in pigeon's brain and a new method that I developed for estimation of "free" and "bound" acetylcholine. He suggested me to publish my findings in a good international journal, and to join some established foreign laboratory. I followed his advice and published in the British Journal of Pharmacology ${ }^{2}$, Canadian Journal of Physiology and Pharmacology ${ }^{3}$, and Neurophysiology ${ }^{4}$. Also, in 1970 I left Sarajevo and joined the most active peptide laboratory in the USA, where worked for two years with Ervin G. Erdos ${ }^{5}$. In 1982, von Euler was my guest at the Department of Pharmacology. He intended to help us to build an international medical research center in Tuzla (Fig.3). Unfortunately, he dpied the following year.

Figure 1. U.S. von Euler at the substance $P$ symposium, Sarajevo, Jun $9^{\text {th }}$ and $10^{\text {th }}, 1961$. Photo: F. Lembeck.

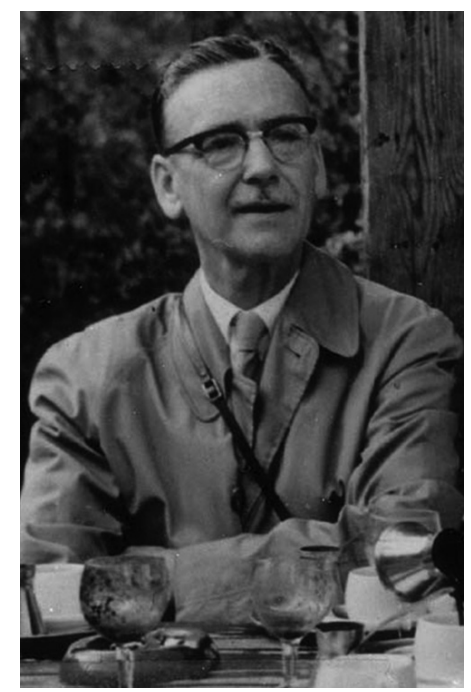


Figure 2. Participants at the symposium on substance $P$ (held in Sarajevo, June $9^{\text {th }}$ and $\left.10^{\text {th }}, 1961\right)$. The symposium was presided by Professor Pavao Stern from the Institute of Pharmacology and Toxicology, Sarajevo. Standing: M.P. Milošević (second from the right), U.S. von Euler (third), S. Huković (fourth), K. Lissak (fifth), P. Stern (sixth). This photo was taken by John Gaddum. I found it among the discarded papers from the Professor Stern's office after his death.

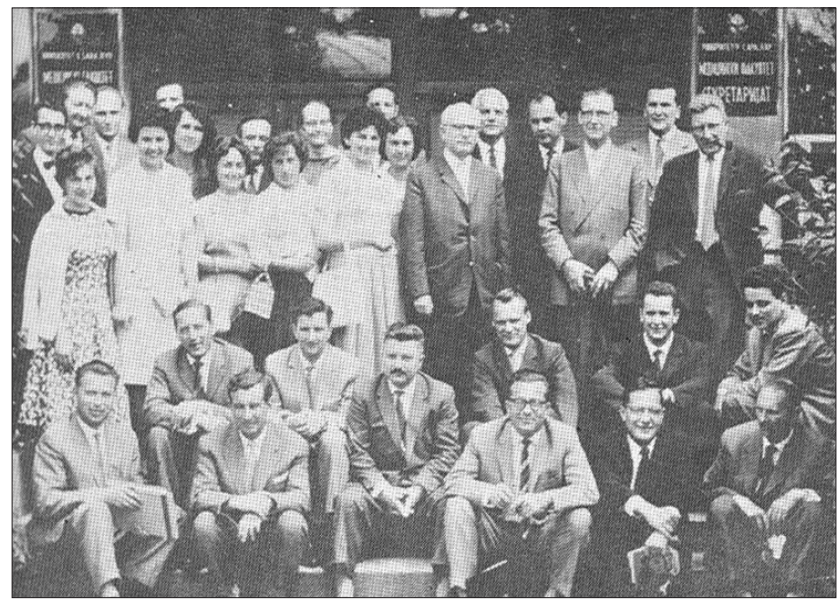

Figure 3. The last letter I received from Ulf Svante von Euler
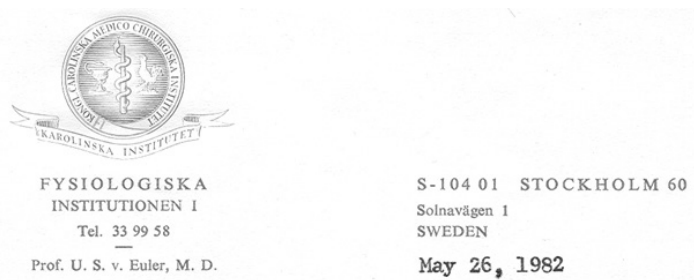

Professor Rajko Igić

Department of Pharmacology

Medical. School

University of Tuzla

YU-75000 TUZLA

Dear Rajko,

I wish to thank you warmly for all kindness and hospitality shown during my visit to your attractive country. It was in every respect a most pleasurable and rewarding experience.

I appreciated the booklet you and your colleagues had prepared very much indeed, remingding me of enjoyable visits in your country.

In addition to the interesting visit to your Department you had arranged such enjoyable items as the Art gallery and to meet its director-painter. Also the visit at the rest house in the mountains was very enjoyable.

Hoping to meet you soon again and with best wishes to you and family.

\section{Conclusion}

Ulf Svante von Euler's scientific achievements show how a young researcher can develop and enhance his research capabilities. In several established research laboratories, he learned the most modern techniques and how to attack prominent scientific problems of the time. Later on, he shared his experiences with many other scientists. Direct interactions between junior and established scientists enable young scientists to develop their skills and better contribute to science. Thus, we need to increase continuing exchange programs financed by governments, organizations that support science, and universities. Greater scientific progress in both developed and developing countries will be the ultimate reward for such activities.

\section{References}

1. Igić R. Remembrances of Ulf Svante von Euler. Acta Physiol (Oxf). 2018; doi.org/10.1111/apha.13098.

2. Igić R. Effect of oxotremorine on the acetylcholine content of whole brain and various brain regions in the pigeon. Br J Pharmacol 1971;42:303-4.

3. Igic R, Stern P. The effect of oxotremorine on the "free" and "bound" brain acetylcholine concentrations and motor activity inberi-beri pigeons. Can J Physiol Pharmacol 1971;49:985-7.

4. Igić R, Stern P, Bašagić E. Changes in emotional behavior after application of cholinesterase inhibitor in the septal and amygdala region. Neuropharmacology 1970;9:73-5.

5. Igić R. An exploration of bioactive peptides: $\mathrm{My}$ collaboration with Ervin G. Erdos. J Biol Chem 2018; 293:7907-15.

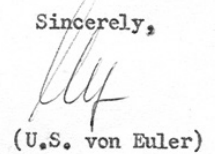

